\title{
Um regime único de aposentadoria no Brasil: pontos para reflexão
}

\author{
Rosa Maria Marques \\ Professora do Departamento de Economia \\ e do Programa de Estudos Pós-Graduados em Economia Política da PUC-SP \\ Alain Euzéby \\ Professor do Instituto de Estudos Políticos de Grenoble
}

\section{Palauras-chave}

aposentadoria de base, regime único, piso e teto para aposentadoria, nível de cobertura.

Classificação JEL I31, I38.

Key words

retirement base, unified system, retirement base and ceiling, level of coverage.

JEL Classification I31, I38.

\section{Resumo}

Este artigo discute, numa primeira parte, o conceito de aposentadoria de base, sua diferença em relação à renda mínima garantida $\mathrm{e}$ à proposta do Banco Mundial, e o de aposentadoria complementar, que está associada à aposentadoria de base. Na segunda parte, à luz da discussão anterior, relaciona o conceito de aposentadoria de base à realidade brasileira, mostrando as dificuldades de sua implantação, bem como o rebaixamento do teto e a adoção de um sistema único. Também o artigo associa o baixo nível de cobertura ao padrão "latino-americano" do mercado de trabalho brasileiro e à ausência do Estado na regulamentação e controle das relações sociais, e sugere formas para sua ampliação.

\section{Abstract}

In the first section, this article discusses the concept of base retirement, its difference in relation to secured minimum income and to the World Bank's proposal, and complementary retirement, which is associated with base retirement. In the second section, in keeping with the previous discussion, it relates the concept of base retirement to Brazilian reality, showing the difficulties of its implementation, as well as the lowering of the retirement ceiling and the adoption of a unified system. This article also associates the low level of coverage to Brazil's Latin American-style work market and the omission of the State in terms of regulation and control of social relations, and it suggests new ways to augment coverage. 


\section{1_Introdução}

A idéia de empreender uma reforma previdenciária que promova a unificação dos diferentes regimes atuais - do setor privado da economia, do funcionalismo público federal, do Judiciário, da magistratura, dos militares e dos deputados federais e dos senadores, entre outros, não é nova. No Brasil, na metade dos anos 1990, essa proposição foi encaminhada ao Congresso Nacional pelo deputado federal Eduardo Jorge, ${ }^{1}$ então do Partido dos Trabalhadores. $\mathrm{O}$ que animava sua proposição era a idéia do tratamento igual no campo da aposentadoria, independentemente, portanto, do gênero, da atividade exercida pelo indivíduo e de sua inserção ao mercado de trabalho do setor privado ou do setor público.

Em outros países, também essa discussão não é nova, seja porque há muito foi implementada, seja porque faz parte das proposições atuais de diversos governos. Além disso, essa preocupação também faz parte, há bastante tempo, da agenda do Banco Mundial no campo social.

No caso brasileiro, a implementação de um regime único para a aposentadoria não é tarefa fácil. Ao contrário, além das fortes reações políticas e sindicais que certamente ocorrerão, há diversas dificuldades estruturais de natureza econômica que não podem ser desconsideradas. Ademais, sua formação histórica e social é resultado de processos completamente distintos daqueles dos países que promoveram a construção dos atuais sistemas de cobertura do risco velhice, nos quais os critérios de acesso à aposentadoria são iguais para todos.

Apesar dessas dificuldades, a proposta de um regime único já estava presente no programa de campanha de Luiz Inácio Lula da Silva e, com ênfase, foi utilizada na discussão da reforma previdenciária do funcionalismo público. Hoje essa proposição não aparece com destaque na agenda governamental, mas continua integrando a idéia de proteção social defendida pelo governo Lula. Numa situação política mais adequada, certamente sua discussão retornará com todos os seus contornos.

Este artigo tem um duplo objetivo: auxiliar no levantamento das dificuldades e dos constrangimentos que uma eventual proposta de unificação dos regimes venha a enfrentar; e considerar as diferentes formas institucionais que uma proposta de equalização no tratamento da aposentadoria possa assumir. A principal preocupação que move essa contribuição é a convicção de que reformas como a da aposentadoria - que alteram
Eduardo Jorge

atualmente secretário da Secretaria de Verde e Meio Ambiente do município de São Paulo. 
significativamente a maneira como as pessoas se relacionam com sua renda da vida ativa e inativa, com impacto presente e futuro sobre o padrão de consumo e de poupança - exigem um processo de discussão que considere não apenas os aspectos econômicos e financeiros envolvidos, mas também os conceitos de justiça social e de solidariedade, princípios básicos da construção da cidadania em qualquer país democrático.

A preocupação em tratar os trabalhadores de forma igual no momento da aposentadoria evoca questões que tangenciam a simples proposta de um regime único. Por isso, a primeira parte deste artigo discute o conceito de aposentadoria de base, salienta suas diferenças com relação à renda mínima garantida e à proposta do Banco Mundial; discute o conceito de aposentadoria de base no interior do atual RGPS e a necessidade da instituição de uma aposentadoria complementar à aposentadoria de base. A segunda parte procura estabelecer a ligação entre os conceitos discutidos na primeira parte e a realidade brasileira. Nela são abordadas questões relacionadas à aplicação de uma aposentadoria de base ou do rebaixamento de teto, a garantia do piso sem anterior contribuição e a receita fiscal, o nível de cobertura e a implantação de um regime único.

\section{2_A aposentadoria de base: concepção e relações com outras propostas similares}

\section{1_A concepção}

A garantia de uma aposentadoria de base apresenta certa relação com o conceito de cidadania, mas, como exploraremos mais adiante, apenas a um conceito restrito, que reconhece a cidadania com base no exercício do trabalho. Seu fundamento é que todo cidadão, independentemente de sua trajetória no mercado de trabalho, tem direito a uma mesma renda de substituição no momento em que sua capacidade para o trabalho diminui, isto é, quando da velhice. O montante pago a título dessa renda de substituição, chamado de valor da aposentadoria, reflete a percepção da sociedade em relação ao que seja o adequado para um indivíduo viver dignamente quando aposentado. Essa percepção é, como não poderia deixar de ser, resultado das diferentes pressões e forças sociais presentes na sociedade.

O financiamento da aposentadoria de base pode se realizado por meio de contribuições de empregados e empregadores ou mediante o aporte de recursos fiscais ou, ainda, de uma combinação de tributos - contributivos (não apenas a folha de salários, mas incluindo as demais contribuições sobre faturamento e lucro 
líquido) e fiscais - tal como preconizado na Constituição de 1988 no capítulo da Seguridade Social. Contudo, como a aposentadoria de base está associada ao conceito restrito de cidadania, entendendo o valor a ser recebido como uma renda de substituição, isto é, que está associada a trabalho anterior, não se justifica que a despesa seja financiada por toda a sociedade. Na medida em que as contribuições constituem rendas diferidas dos trabalhadores, muito embora as empresas possam repassar os custos de suas contribuições aos preços, a aposentadoria de base deve ser financiada por elas.

Os fundamentos que estão subjacentes ao direito à aposentadoria de base são: a sociedade salarial, isto é, a do trabalho, e a justiça social. A sociedade salarial constitui o fundamento primeiro, uma vez que o acesso ao beneficio pressupõe a perda de capacidade laboral. ${ }^{2} \mathrm{~A}$ justiça social é realizada pelo exercício da solidariedade, na medida em que o conjunto dos trabalhadores financia a aposentadoria de base. Dessa maneira, os trabalhadores de mais baixa renda não são estigmatizados, como pode ocorrer quando o valor leva em consideração a capacidade contributiva. Note-se que o conceito de justiça social, tal como o da cidadania, presente na aposentadoria de base, tam- bém é restrito, já que se resume a considerar um valor base de aposentadoria para todos, desde que tenham previamente trabalhado.

\section{2_ A aposentadoria de base \\ e a garantia de uma renda mínima}

A aposentadoria de base não pode ser confundida com a renda mínima garanti$\mathrm{da}$, visto que o critério de acesso de cada uma delas tem fundamento diferente. $\mathrm{Na}$ medida em que o acesso à aposentadoria de base somente é conferido a quem tiver anteriormente trabalhado, trata-se de um direito obtido pelo mérito, o de ter trabalhado, e por isso está estreitamente associado ao mundo do trabalho ou à sociedade salarial. A cidadania (conceito restrito), presente no valor da aposentadoria de base, significa que, independentemente da renda e da capacidade contributiva do trabalhador, lhe será pago o valor de base.

A renda garantida é apresentada, na literatura internacional e brasileira, com diversas nuanças e justificativas (Marques, 1997 e Suplicy, 2002). De maneira geral, contudo, é defendida como um direito a que todo cidadão tem em qualquer momento de sua vida. Nesse sentido, o direito decorre diretamente do conceito de cidadania, e não está condicionado a tra-
2 Na sociedade salarial, o exercício de uma atividade remunerada encontra seu contrário no desemprego e na velhice. 
balho anterior e à perda da capacidade laboral na velhice.

Tanto a garantia de uma renda mínima como a de um valor de base para a aposentadoria constitui um instrumento de redistribuição de renda em favor dos segmentos menos favorecidos da população. No entanto, enquanto na aposentadoria de base a distribuição de renda é financiada pelos trabalhadores e ocorre entre eles, a renda mínima garantida envolve toda a população. Por isso seu financiamento somente pode ser pensado em termos de recursos fiscais, uma vez que é essa a única maneira de excluir a possibilidade de a carga recair apenas sobre um dos segmentos da sociedade ou sobre apenas um fator de produção.

\subsection{A aposentadoria de base e a proposta do Banco Mundial}

A proposta do Banco Mundial para o risco velhice foi apresentada, pela primeira vez, em seu relatório "Envejecimiento sin crisis: políticas para la protección de los ancianos y la promoción del crecimiento", de 1994. Nesse relatório, a instituição defende que o Estado deve-se restringir, no campo da aposentadoria, a garantir modestos valores, e que esses podem ser estendidos a todos ou focalizados nas pessoas de baixa renda, median- te teste de meios. Tal como é destacado por Beattie e McGillivray (1995), a preferência do Banco Mundial fica com a segunda alternativa, já que o objetivo primeiro do banco é construir um sistema de três pilares, como ficou conhecido na literatura de políticas sociais. Dessa forma, a proposta de uma aposentadoria de valor relativamente baixo, dirigida preferencialmente ao setor de baixa renda da população, é completada por um regime complementar obrigatório privado, de contribuição definida, e por uma poupança facultativa.

A concepção do Banco Mundial, cujo "balão de ensaio" foi a reforma realizada no Chile, tem por fundamento a "crença" de que um sistema de pensões capitalizado eleva a poupança nacional, o que estimularia o investimento produtivo e o crescimento econômico. O segundo fundamento é pensar que a concorrência do mercado determinará maior eficácia na gestão. Em relação ao financiamento, a aposentadoria de base teria como fonte recursos fiscais; a aposentadoria complementar, a contribuição exclusiva dos trabalhadores.

Tendo em vista o tempo decorrido desde o início da implantação da reforma chilena, já dispomos de elementos suficientes - são inúmeros os artigos que 
fazem um balanço da aplicação dessa experiência - para dizer que, pelo menos no que se refere à proteção social, ${ }^{3}$ aumentou a situação de desamparo, sendo crescente a quantidade de aposentados que, no momento da aposentadoria, não acumularam fundos adequados para "comprar" uma aposentadoria de base no setor privado, o que determina seu retorno ao Estado. Essa situação caracteriza aquilo que se chama verdadeiramente de privatização financiada pelo Estado.

No conjunto da América Latina, sob a tutela do Banco Mundial, 12 países reformaram seu sistema de aposentadoria entre 1981 e 2004: Argentina (1994), Bolívia (1998), Chile (1981), El Salvador (1997), México (1997), Peru (1992), Uruguai (1996), Colômbia (1993), Costa Rica (2000), Nicarágua (2000), Equador (2001) e República Dominicana (2003). Segundo Ferranti e outros (2002), ao analisarem as primeiras experiências empreendidas, os regimes reformados obtiveram sucesso significativo nos primeiros anos de atividade, sob o ponto de vista do volume de ativos administrados pelas Caixas de aposentadoria privada e do rendimento bruto. Ao mesmo tempo, contudo, os autores (que claramente se manifestam como favoráveis aos regimes privados capitalizados) destacam que as reformas não possibilitaram a redução da pobreza entre as pessoas idosas, e que o número de contribuintes continua extremamente baixo. Em outras palavras, as reformas não atingiram os objetivos sociais declarados pelo Banco Mundial, mas possibilitaram o desenvolvimento de novo campo de acumulação na América Latina e originaram reformas no setor financeiro.

Destaque-se que o próprio Banco Mundial, em seu relatório "La promesa de seguridad de los ingresos en la vejez en América Latina", disponibilizado em 2004, concluiu que as reformas empreendidas não foram bem-sucedidas no que se refere à ampliação da cobertura, isto é, no propósito da universalização. Além disso, entre outros aspectos, sugere que os governos prestem mais atenção para assegurar que os planos de pensão privados "ofereçam aos trabalhadores filiados e a suas famílias a melhor cobertura possível a preços competitivos". $\mathrm{Na}$ linguagem muitas vezes cifrada dessa instituição, isso significa o reconhecimento de que o nível de cobertura não é o mais adequado.

\subsection{A aposentadoria de base no atual Regime Geral da Previdência Social}

A introdução do piso correspondente a um salário mínimo pela Constituição de 1988 - e que foi mantido na reforma realizada posteriormente - guarda certa $\because \cdots \cdot \cdots \cdot \cdots \cdot \cdot \cdot \cdots$

Também outros aspectos não se comprovaram, tal como a eficácia do mercado na gestão dos Fundos, entre outros. 
relação com a concepção de uma aposentadoria de base, tal como descrita anteriormente. Contudo, essa relação expressa-se tão-somente na garantia de que o valor mínimo da aposentadoria a ser percebido não pode ser inferior ao salário mínimo, ${ }^{4}$ diferindo em relação aos outros aspectos.

Sem entrar no mérito se seu valor é ou não adequado, interessa aqui destacar que não é desprezível o número daqueles que recebem o piso correspondente a um salário mínimo, sem que sua participação direta no financiamento do sistema, isto é, sua contribuição ao longo da vida ativa, permitisse-lhe, em termos atuariais, uma aposentadoria de valor igual ao salário mínimo. Entre eles, (redação dada pela Lei n. 9.528, de 10 de dezembro de 1997).

No Brasil, tal como em outros países, essa contribuição é de difícil fiscalização.

6 É importante destacar que não se está aqui falando dos benefícios pagos pela Lei Orgânica de Assistência Social (LOAS) às pessoas com 65 anos ou mais e a portadores de deficiência que lhes impeçam de ter vida independente ou de trabalhar, cuja renda familiar per capita é inferior a $25 \%$ do salário mínimo. encontram-se trabalhadores rurais que nunca contribuíram, ${ }^{5}$ mas também trabalhadores urbanos com salário correspondente ao salário mínimo. ${ }^{6}$

Nesse caso, a garantia de uma aposentadoria de base é praticada conquanto valor mínimo, restrito àqueles sem capacidade de contribuição suficiente. Além disso, o piso foi financiado pelas contribuições desde o início, de maneira que, na prática, foram e são os trabalhadores do mercado formal de trabalho que sustentaram sua implantação. Tendo em vista que os trabalhadores rurais, mesmo não tendo contribuído anteriormente, tiveram direito ao piso de acordo com o entendimento de que nenhum trabalhador poderia receber aposentadoria menor do que o salário mínimo, teria sido mais apropriado e adequado, como contrapartida desse reconhecimento, que fossem financiados por recursos fiscais. No caso dos rurais, como será visto a seguir, o volume arrecadado a título de sua contribuição fica bastante aquém das suas despesas. Contudo, o entendimento de que melhor seria garantir o piso tomandose por base recursos fiscais não decorre dessa situação, e sim do entendimento de que o piso, nesse caso e quando associado a trabalhador que contribuiu sobre um salário mínimo, assemelha-se ao conceito de renda mínima e, por isso, deveria ser assim financiado. 
A comparação entre a receita de contribuições oriunda da clientela rural e a despesa com benefícios da mesma clientela, largamente formada por aposentadorias de valor igual ao salário mínimo, mostra a magnitude da "distribuição de renda" que é realizada entre os trabalhadores integrantes do RGPS. Segundo o próprio Ministério da Previdência Social, depois de instituído o piso, a receita de contribuição dos rurais nunca representou mais do que $13 \%$ do total da despesa com os benefícios rurais até 1997 (Ornelas, 1999). Essa relação foi de $9,8 \% \mathrm{em}$ 1998 e de 6,3\% em 2000. Em 2003, no entanto, a capacidade de "autofinanciamento" 7 do regime rural melhorou, passando a representar $13,8 \%$ do total da despesa com seus benefícios.

\section{5_A necessária complementação da aposentadoria de base}

Uma aposentadoria de valor base pressupõe a existência de um regime complementar de aposentadoria, o qual pode ser público ou privado, facultativo ou obrigatório, por capitalização ou repartição, financiado somente pelos trabalhadores ou também pelos empregados e empregadores. ${ }^{8}$

Nunca é demais repetir e enfatizar o que diferencia a aposentadoria em regi- me de repartição das do tipo seguro. A principal diferença reside no fato de ela ser financiada por contribuições obrigatórias que são definidas como coletivas na sua natureza. Essa diferença implica que não há, portanto, correspondência direta ou imediata entre o esforço contributivo do trabalhador (o que ele paga ao longo da vida ativa) e o que ele irá receber quando, por exemplo, se aposentar. A proteção organizada pelo Estado, da qual o RGPS é um exemplo, constitui um sistema de solidariedade coletiva, não mais e não menos do que isso (Euzéby, 1997). Contudo, para os críticos desse sistema, a não-correspondência perfeita entre as con- 
9 A literatura é extensa sobre essa época. Para quem quiser se aprofundar sobre o processo de formação dos sistemas de proteção social nos principais países desenvolvidos, sugere-se a leitura de Esping-Andersen (1991). Este artigo, embora pequeno, resume bem o processo. tribuições e o benefício é suficiente motivo para justificar sua substituição por qualquer outra forma de poupança privada ou de seguro, que obedeçam às leis de mercado. Eles não compreendem, ou não consideram relevante, que a aposentadoria pública, em regime de repartição, é um mecanismo de solidariedade baseado no princípio da distribuição de renda.

O fato de esse mecanismo ser imposto pelas autoridades públicas aos indivíduos e às famílias é outro alvo de crítica e justificativa para sua eliminação. No passado, quando os sistemas públicos estavam para ser implantados, o debate foi intenso e prevaleceu, tendo em vista o peso dos sindicatos e dos partidos vinculados aos trabalhadores, a concepção solidária obrigatória. ${ }^{9}$ Sem querer retomar essa discussão, registre-se apenas que a poupança privada, realizada livremente pelo indivíduo, tem alguns "inconvenientes" tais como:

a. é baseada na responsabilidade individual, na qual cada um atua conforme vê e compreende sua situação, portanto de acordo com sua visão sobre a que riscos está exposto;

b. a poupança somente é possível entre os indivíduos e as famílias com suficiente renda disponível; c. faz parte da natureza humana, em uns mais do que em outros, ter forte preferência para viver o presente e não se precaver com relação a futuras necessidades ou vicissitudes que possam ocorrer.

Dessa compreensão derivou a construção de uma proteção social obrigatória e solidária. É interessante lembrar, uma vez que auxilia a compreender melhor a extensão dessa concepção, que o direito à renda, em caso de perda de capacidade laboral (seja por velhice, invalidez, seja por doença e desemprego), está inscrito na Declaração dos Direitos Humanos, aprovada em 1948 pela Assembléia Geral das Nações Unidas (Euzéby, 1997).

É essa forma de pensar a proteção aos riscos que explica por que, no interior de um sistema solidário, é possível o pagamento de um piso acordado na sociedade mesmo àqueles que, através de seu esforço contributivo, não teriam "direito" a ele, se fosse levada em consideração a lógica do mercado e o cálculo atuarial, tal como é o caso do piso de um salário mínimo no Brasil. Seria desnecessário dizer, mas é sempre importante reafirmar que, em políticas públicas, um regime solidário é, por principio, um regime de repartição. A solidariedade ocorre entre as gerações e os integrantes de uma mesma geração. 
Ainda em relação à complementação da aposentadoria, a mesma necessidade surge quando o sistema, embora público, contributivo e de repartição, com o concurso dos trabalhadores e dos empregadores, tem como teto do benefício a ser pago valor relativamente baixo com relação aos salários dos trabalhadores ativos. Esse é o caso da França, onde o regime complementar é obrigatório, de repartição, administrado de forma conjunta pelos trabalhadores e pelos empregadores e financiado por meio das contribuições desses dois segmentos. Vale lembrar, no entanto, que, quando a obrigatoriedade foi introduzida, em 1972, isso não provocou nenhuma mudança substantiva, visto que os regimes complementares já abrangiam largamente a maioria dos trabalhadores.

O exemplo da França serve para ilustrar quando é apropriada a utilização de regimes complementares obrigatórios: quando os valores pagos a título de aposentadoria representam parcela pouco significativa da renda/salário dos trabalhadores. Em outras palavras, quando o regime geral tem teto relativamente baixo, tanto para o valor da aposentadoria a ser pago como para a contribuição do trabalhador.

\section{3_Questões a ser consideradas para a adoção de um regime geral de aposentadoria no Brasil}

\section{1_Aposentadoria de base ou rebaixamento do teto?}

A adoção de uma aposentadoria de base financiada por recursos fiscais está fora de cogitação no Brasil, no momento. Isso porque o governo eleito, a princípio, não pode aumentar o nível de despesas, uma vez que enfrenta a restrição do superávit primário, seja por exigência do Fundo Monetário Internacional, seja porque o elegeu como variável-chave da trajetória futura da economia brasileira. Com muito mais razão, se pensarmos em garantir, na velhice, uma renda digna para todos, financiada por recursos fiscais.

Considerando apenas a aposentadoria de base, mas financiada mediante recursos fiscais, e se, por hipótese, entendermos que seu valor base corresponderia ao do salário mínimo, isto é, se o atual piso viesse a ser a referência para o valor base, o volume de recursos necessários seria extremamente alto: em dezembro de 2003, no atual RGPS, foram pagos 21,9 milhões de benefícios. Deste total, 12,1 milhões corresponderam a aposentadorias, e 5,5 milhões a pensões por morte. 
Uma seguinte alternativa seria a de reduzir o teto dos benefícios pagos pelo regime atual (mantendo o financiamento mediante contribuições), na perspectiva de um regime geral e da implantação de um regime complementar obrigatório. No passado recente, não foram poucas as propostas que sugeriam a restrição do teto a 3 ou a 5 salários mínimos. Todas elas, no entanto, tinham como objetivo introduzir a aposentadoria complementar obrigatória e capitalizada. Eram motivadas pela idéia de que isso possibilitaria a formação de substancial poupança nacional e o desenvolvimento do mercado financeiro. Essas proposições não receberam eco na sociedade por diferentes motivos, entre eles o fato de não considerarem o enorme custo de transição que deveria ser financiado pelo Estado.

Deixando de lado esse aspecto fundamental e, portanto, raciocinando apenas como exercício, a pergunta que devemos fazer é se o leque de renda abrangido pelo atual sistema RGPS é inadequado ou não. Do lado da contribuição do trabalhador, temos atualmente quatro níveis de alíquotas que variam entre 7,65 a $11 \%$, e o teto corresponde atualmente a $\mathrm{R} \$ 2.508,72$. Do lado dos valores pagos em termos de aposentadoria, o mínimo corresponde a um salário mínimo, e o máximo a $\mathrm{R} \$ 2.508,72$. O de que precisa- mos saber, e o Ministério da Previdência e Assistência Social (MPAS) dispõe dessa informação, é quanto representam aqueles que contribuem para o sistema com salários acima de 3 salários mínimos, na primeira alternativa, e quanto representam aqueles com salários ou renda acima de 5 salários mínimos. Do lado dos benefícios, sabemos que, em 1999, por exemplo, do total dos benefícios concedidos, 81,3\% correspondiam a até 3 salários mínimos. Junto à clientela rural, esse percentual atingia 99,5\% e, entre a urbana, $73,3 \%$. Para esse mesmo ano, quando o valor é ampliado para até cinco salários mínimos, a participação dos benefícios alcançava 86,3 e 99,9\%, respectivamente, para as clientelas urbana e rural. Ainda nesse mesmo ano, o valor médio das aposentadorias recebidas no Estado de São Paulo era de 2,9 salários mínimos.

Esse conjunto de informações demonstra que os valores das aposentadorias do atual RGPS, na medida em que guardam certa relação com a capacidade contributiva, são tão baixos quanto os salários da maioria da população brasileira. Ante a realidade desses dados, qual o propósito e a eficácia de uma proposta de redução de teto?

Dessa maneira, parece inadequada, para a realidade brasileira, tanto a adoção de uma renda digna para todos na 
velhice (mantida a restrição da geração do superávit primário) como a redução do teto. Da discussão inicial a que se propôs este artigo, permanecem, contudo, três aspectos. $\mathrm{O}$ primeiro deles é que, no interior do atual RGPS, o piso de um salário mínimo constitui um valor de aposentadoria de base que está garantindo esse nível mínimo de aposentadoria para quem nunca contribuiu (ou tinha baixa capacidade de contribuição) e que está sendo financiado em parte pelas contribuições dos trabalhadores, consistindo em uma redistribuição de renda entre os trabalhadores. Tal prática não é a forma mais apropriada e mais justa, principalmente quando se leva em conta o nível dos salários dos trabalhadores brasileiros.

Por isso, um governo que desejasse avançar na construção de uma proteção social poderia resgatar o princípio de justiça social e de solidariedade no sentido mais amplo, garantindo o financiamento do piso, tal como em outros paises, através de recursos fiscais. Havendo restrições orçamentárias, essa seria a oportunidade de introduzir uma contribuição de solidariedade, aos moldes do que existe na França. Dito de outra forma, reparar a injustiça atualmente existente, que faz a sustentação do piso recair apenas sobre o trabalho, significa exigir que o conjunto da sociedade financie o piso daqueles que nunca contribuiram. ${ }^{10}$
O segundo aspecto diz respeito a se podemos, de fato, dizer que o Brasil dispõe da cobertura do risco velhice. Em 1998, de acordo com Pinheiro (2000), a cobertura, considerando todos os regimes, atingia apenas $40,9 \%$ da população ocupada, pouco superior à do México e à do Equador (36\%) e longe da existente no Uruguai (69\%) e nos países da OCDE (mais de 90\%). Um ano antes, cerca de $62 \%$ da população ocupada não contribuíam para o RGPS, e 56\% não contribuíam para nenhum tipo de Previdência. Vale lembrar que o desenvolvimento do mercado informal é crescente nos anos de crise e estagnação: entre 1991 e 2001, a participação dos assalariados sem carteira de trabalho passou de 20,8\% para $27,1 \%$, e, dos chamados autônomos, de $20,1 \%$ para $23 \%$, segundo o IBGE. Nesse mesmo ano, 40,7 milhões de ocupados do setor privado da economia não eram contribuintes do RGPS ou de qualquer tipo de outro regime, o que correspondia a $57,7 \%$ da população ocupada nesse setor, nesse ano.

Esses dados, que refletem a realidade de nosso mercado de trabalho, mostram o verdadeiro desafio que o governo deveria enfrentar no campo da aposentadoria: como aumentar o nível de cobertura no País.

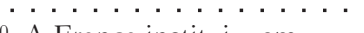

10 A França instituiu, em 1991, a Contribuição Social Generalizada (CSG) também chamada de contribuição de solidariedade. $\mathrm{Na}$ origem, a CSG consistia em 1,1\% calculado sobre todas as rendas, cuja arrecadação era vinculada aos benefícios destinados às famílias. Dois anos depois, a alíquota passou a $1,3 \%$, e a destinação de sua receita foi ampliada, abrangendo a cobertura do risco velhice, mais especificamente a renda mínima velhice para aqueles que não contribuíram anteriormente. Em 1997/1998, a alíquota foi aumentada para $4,1 \%$, e sua arrecadação começou a ser também destinada ao risco doença (Euzéby, 1991; Sterdyniak e Villa, 1998).
} 
Essa realidade - de grande presença do trabalho informal - é um traço característico dos países da América Latina, que, ao contrário da Argentina, do Uruguai e do Chile, tiveram trajetória diferente no passado, no que se refere ao peso político dos trabalhadores na definição de seus direitos. ${ }^{11}$ No caso brasileiro, objeto deste artigo, um dos maiores desafios é trazer para a formalidade o assalariamento sem carteira de trabalho, mas também os autônomos. E os motivos que ocasionam tal situação são bastante diferentes.

A existência de contingente significativo de assalariados sem carteira assinada é sinal, em primeiro lugar, da fraca presença do Estado na regulação e no controle da economia e de suas relações. Os empregadores que não assinam a car- teira de seus trabalhadores estão, na maior parte das vezes, na ilegalidade, no que diz respeito a suas outras obrigações, especialmente em relação ao fisco. $\mathrm{O}$ segundo grande motivo, entre outros, é a fraqueza relativa da organização dos trabalhadores brasileiros vis-à-vis os do Cone Sul, já citados. Nas categorias de trabalhadores onde há uma tradição de luta e o nível de organização é grande, dificilmente encontraremos tamanho peso do trabalho informal. Diante disso, somente o esforço conjunto do Estado e dos trabalhadores poderá alterar essa realidade. Buscar as formas para que os controles sejam efetivos é tarefa do novo governo.

Quanto aos chamados autônomos, ${ }^{12}$ a tarefa é ainda mais complexa, uma vez que envolve componentes de outra natureza. Isso porque a adesão ao

\footnotetext{
11 Atualmente, tendo em vista a implementação de políticas neoliberais, os três países se defrontam com o mesmo problema, com uma baixa taxa de contribuição e de cobertura da Previdência Social. Talvez a situação mais emblemática seja, hoje, a da Argentina. Mesmo no Chile, onde a implementação de um regime privado e de capitalização por algum tempo foi anunciada como o exemplo exitoso
}

$\begin{array}{ll}\text { da "modernidade", a } & \text { contribuição. A proposta de } \\ \text { cobertura das Administradoras } & \text { emenda constitucional da } \\ \text { de Fondos de Pensiones (AFPs) } & \text { Previdência, chamada de PEC } \\ \text { não passa de 40\%, e a } & \text { Paralela, sugere a redução } \\ \text { dificuldade de incorporar os } & \text { dessa alíquota para 11\% sobre } \\ \text { informais é significativa } & \text { o salário mínimo, quando não } \\ \text { for o caso de trabalhador que } \\ \text { maio de 2003, definiu a } & \text { eventualmente presta serviços } \\ \text { contribuição do autônomo, } & \text { a empresas. Em 22 de junho } \\ \text { bem como de todos que } & \text { de 2005, o senador Rodolpho } \\ \text { integram a categoria de } & \text { Tourinho (PFL-BA) } \\ \text { contribuinte individual, como } & \text { informava ao plenário que } \\ \text { sendo 20\% sobre o salário de } & \text { apresentaria à Comissão de }\end{array}$

\author{
Cidadania (CCJ) seu parecer \\ nas próximas 48 horas. Entre \\ outras modificações, a PEC \\ Paralela - Proposta de \\ Emenda Constitucional \\ 77A/03, encaminhada \\ na sua primeira versão \\ ao final de 2003 -, busca \\ minimizar os efeitos da \\ reforma da Previdência do \\ setor público, encaminhada \\ pelo governo Lula.
}


RGPS, ou a qualquer outro regime, é voluntária, o que determina a necessidade do enfrentamento tanto da imprevidência daqueles que tendem a considerar que o futuro, quando a velhice fizer valer a sua força, está muito longe, quanto da falta de confiança que o brasileiro tem, em geral, em relação as suas instituições. $\mathrm{Na}$ história da construção dos sistemas de proteção social, o primeiro aspecto, presente em qualquer segmento da população, foi resolvido mediante a instituição da obrigatoriedade. O segundo, isto é, a segurança em relação à instituição da proteção social pública ou dos regimes de seguro para a aposentadoria foi construída ao longo do tempo de demonstração efetiva de sua proteção. Em relação a isso, o fato de o Brasil, durante os últimos 16 anos, estar discutindo a reforma e promovendo modificações na legislação relativa à aposentadoria e aos demais benefícios - seja do RGPS, seja do funcionalismo público contribui para a perda de confiança em relação ao sistema público.

Uma "solução" para instituir a obrigatoriedade seria exigir que em todas as atividades onde habitualmente precisa-se informar o número do registro geral, isto é, da identidade, fosse informado do número de registro ao regime público. Para essa medida entrar em vigor, seria dado um prazo que possibilitasse os acertos devidos (para as empresas registrarem seus trabalhadores e para os autônomos se inscreverem no sistema). No caso dos autônomos, seria lhes exigido apenas uma adesão contributiva que lhes garantisse, no futuro, o piso da aposentadoria. Medida desse tipo, por mais autoritária que seja, precisa, no entanto, do amplo apoio da população e de seus diferentes segmentos. Campanhas esclarecedoras e o engajamento de setores, tais como o comercial, o bancário, o de lazer, entre outros, são fundamentais.

\section{2_ Um regime único para todos}

A proposta de promover a unificação de todos os regimes em um regime geral não é nova, como mencionado na introdução deste artigo. À parte pela razão de os proventos serem significativamente mais altos em alguns segmentos, tais como entre os juízes, os deputados e os senadores, por exemplo, há a idéia, bastante difundida entre a população brasileira, de que os funcionários públicos são privilegiados, visto que, até há pouco tempo, todos tinham garantido que o valor de sua aposentadoria corresponderia a seu último provento.

O fato de os funcionários públicos terem um regime próprio não é uma realidade apenas brasileira. Quando se volta o olhar para outras experiências fora do Brasil, verifica-se que isso não é uma formação institucional única, carac- 
terística do processo histórico do País. Constata-se, por exemplo, que, na maioria dos países membros da Organização de Cooperação e Desenvolvimento Econômico (OCDE), os funcionários federais são cobertos por regimes de aposentadoria particulares e especialmente concebidos. Esses regimes são totalmente independentes ou complementares ao regime geral nacional. Eles concedem vantagens, em relação ao sistema dos trabalhadores do setor privado, que variam de país a país. Há casos em que, em um mesmo país, co-existem vários regimes, que cobrem as diferentes categorias de funcionários e empregados do Estado.

$\mathrm{Na}$ maioria deles, consistem de regimes de repartição, financiados pelo orçamento do Estado e, em todos eles, os regimes dos funcionários públicos são anteriores aos dos trabalhadores do setor privado da economia. Aliás, é interessante notar que tanto os sistemas de aposentadorias legais de base quanto os complementares derivam do sistema de aposentadoria profissional do setor público. Isso porque o Estado foi o primeiro empregador a organizar a cobertura das necessidades de seus funcionários e dependentes, desenvolvendo sistemas para o caso de velhice, invalidez, entre outras situações.

Segundo relatório divulgado pela OCDE (1997), a maioria de seus países membros construiu a proteção social dos funcionários do Estado considerando que as aposentadorias são rendas prolongadas, mas reduzidas, pagas pelo orçamento do Estado, assim como o são os proventos dos funcionários. Nesse caso, os funcionários que tinham sido agentes do Estado na vida ativa continuavam a ser assim considerados quando aposentados. Isso não implica que os funcionários do Estado não contribuam para o financiamento de sua proteção. O que se quer aqui destacar é o fundamento que originou o tratamento concedido aos funcionários públicos, a de que seus trabalhadores permanecem funcionários públicos por toda a vida, enquanto ativos e enquanto inativos.

Essa concepção, segundo esse relatório, está fundada no fato de as regras que governam a função pública diferirem em todos os aspectos daquelas que regem as relações entre empregadores e empregados no setor privado. Para começar, os funcionários exercem a autoridade pública mais do que simplesmente a representam. Isso acarreta uma série de obrigações e sacrifícios, entre os quais a razão de os salários serem geralmente mais baixos, quando comparados ao do setor privado, para igual nível de qualificação e responsabilidade. Para compensar essa situação, o Estado se comprometeu a cobrir as necessidades dos funcionários pelo res- 
tante de suas vidas. Nesse sentido, a estabilidade, tão falada como um privilégio dos funcionários públicos, estende-se para toda a vida do funcionário público e deriva, historicamente, do caráter da função exercida pelo servidor. Isto é, as condições de emprego e os regimes de aposentadoria corres- pondentes fazem parte integrante das regulamentações aplicáveis às suas funções.

$\mathrm{Na}$ medida em que o beneficio de aposentadoria é considerado uma renda que se prolonga para o período de inatividade do funcionário público, a base de cálculo é, geralmente, o provento de fim de carreira, e seu valor corresponde, em média, a 75 - $80 \%$ do provento líquido. Dessa forma, conquanto renda prolongada, a aposentadoria lhe garante um nível de vida similar àquele de quando na ativa. Vale dizer que, quando os funcionários públicos contribuem para o financiamento de seu regime de aposentadoria, os valores aportados consistem somente em aproximações, já que não há nenhuma relação com o valor da aposentadoria, dado que essa é considerada uma renda prolongada.

Considerando esses princípios e realidades dos países da OCDE, verifica-se o grau de complexidade das questões que estavam envolvidas quando o governo Lula encaminhou em 2003 (e conseguiu aprovar) modificações substantivas no regime de aposentadoria dos servidores brasileiros. Essa complexidade torna-se mais aguda ainda quando o horizonte perseguido é a criação de um sistema único, que não faça distinção entre os trabalhadores do setor privado e os do setor público.

Mas serão os funcionários públicos realmente privilegiados? Para responder a essa questão, seria importante que se abandonasse a análise da simples comparação entre os valores das aposentadorias vis-à-vis o último salário ou provento e se passasse a focalizar a comparação entre a totalidade da renda obtida durante a vida ativa e a inativa (quando aposentado) dos dois segmentos de trabalhadores. Embora não seja propósito deste artigo a realização desse exercício, vale destacar quais questões deveriam ser levadas em conta na elaboração desse cálculo. São elas:

1. quanto maior o nível de qualificação e experiência, maior é a diferença entre os salários pagos pelo setor privado e os proventos pagos pelo governo federal;

2. as alíquotas das contribuiç̃ões dos trabalhadores do setor privado são progressivas e submetidas a um teto, enquanto que a dos funcio- 
nários públicos federais, antes da reforma, e sem exceção, consistia de $12 \%$ sobre o total do provento;

3. os trabalhadores do setor privado podem, no momento da aposentadoria, ter acesso ao seu Fundo de Garantia de Tempo de Serviço (FGTS), o que, evidentemente, não é devido ao funcionário público, uma vez que ele conta com a estabilidade.

Considerando essas informações, nossa hipótese é a de que seria bastante provável que, calculada a renda do "ciclo de vida" dos trabalhadores do setor privado e dos funcionários públicos, para igual nível de qualificação, os valores, devidamente atualizados, tenderiam a ser próximos.

Esses elementos indicam a necessidade de uma melhor reflexão sobre proposições que tendam a tratar da mesma forma os funcionários federais e os trabalhadores do setor privado em matéria de aposentadoria. A simples idéia de igualdade de tratamento não parece adequada, já que deixa de considerar que as situações de inserção são verdadeiramente diferentes, isto é, não há como tratar de forma igual situações desiguais.

A instituição de um regime único deveria ser concomitantemente acom- panhada pela mudança do estatuto do funcionário público, de forma que suas obrigações e deveres se igualassem às do trabalhador do setor privado. Em outras palavras, seria necessário que o funcionário público deixasse de ser funcionário público dentro dos termos explicitados acima. Resta saber se isso é possível de ser feito e mesmo desejável.

\section{Notas conclusivas}

A proposição da unificação dos regimes no Brasil suscita discussões sobre a pertinência da adoção de uma aposentadoria de base, a necessidade de ser promovida a ampliação da cobertura do risco velhice e sobre a diferença de estatuto entre os funcionários públicos e os trabalhadores do setor privado.

Tendo em vista a realidade brasileira, a ampliação da garantia do risco velhice para todos enfrenta o constrangimento, no momento definida pelas autoridades governamentais como intransponível, da exigência de realização de superávit primário. Por outro lado, a adoção de uma aposentadoria de base, implicando a redução do teto atualmente existente para os benefícios, também não parece muito adequada. Para tal proposição ser implantada, o valor da aposentadoria de base 
necessitaria ser extremamente baixo em relação aos valores atualmente pagos pelo RGPS, por exemplo. Isso porque a participação relativa do número de benefícios compreendidos nas faixas até 3 ou 5 salários mínimos é extremamente significativa.

Seria desejável, no entanto, que a despesa correspondente ao piso de um salário mínimo, pago a quem nunca contribuiu, fosse financiado por recursos fiscais. Tal modificação, além de corrigir uma injustiça (a de que a redistribuição de renda, que garante o recebimento do piso por aqueles que nunca contribuíram, está sendo financiada somente pelos trabalhadores), seria o embrião de uma futura etapa, aquela do reconhecimento de que todos têm direito a uma renda digna na velhice.

Para a ampliação do nível de cobertura junto aos ocupados, seria necessário que o governo buscasse formas de aplicação do princípio da obrigatoriedade ao chamado setor autônomo, que, ao mesmo tempo, pudessem servir de instrumento de efetivo controle do cumprimento da lei no setor empregador que não registra a carteira de seus trabalhadores. Por mais autoritário que possa parecer para alguns, o princípio da obrigatoriedade foi aquele que permitiu o surgimento dos regimes públicos, tais como os conhecemos.
Em relação aos privilégios dos funcionários públicos, argumento para sua integração a um regime geral, sugere-se maior reflexão. Para isso propõe-se o abandono da simples comparação dos valores das aposentadorias em relação aos salários e proventos, e a adoção da comparação entre a renda percebida durante a totalidade do ciclo de vida. É nosso sentimento que, para o mesmo nível de qualificação, as rendas tendem a ser iguais. 


\section{Referências bibliográficas}

BANCO MUNDIAL.

Envejecimiento sin crisis: políticas para la protección de los ancianos y la promoción del crecimiento. Washington: Banco Mundial, 1994.

BANCO MUNDIAL. La promesa de seguridad de los ingresos en la vejez. en América Latina. Washington: Banco Mundial, 2004.

BEATTIE, R.; McGILLIVRAY, W. Une stratégie risquée: réflexions sur le rapport de la Banque Mondiale, La crise du vieillissement. Revue Internationale de Sécurité Sociale. Genève, Association Internationale de la Sécurité Sociale, v. 48, n. 3-4, 1995.

ESPING-ANDERSEN, G. As Três Economias Políticas do Welfare State, Lua Nova, São Paulo, CEDEC, n. 24, setembro, 1991.

EUZÉBY, Alain. La contribution sociale généralisée (CSG): justifications et perspectives, Droit Social, n. 7/8, juil./août 1991. Paris: Editions Techniques et Economiques, 1991.

EUZEBY, Alain. Social security: indispensable solidarity, International Social Security Review, v. 50, n. 3. Genebra: International Social Security Association, 1997.
FERRANTI, D.; LEIPZIGER, D.; SRINIVAS, P. S. L'avenir de la réforme des retraites en Amérique latine, Finances et Développement, sept. 2002. Washington: Fonds Monétaire International, 2002.

MARQUES, R. M. A proteção social e o mundo do trabalho. São Paulo: Editora Bienal, 1997.

MARQUES, R. M. Salário mínimo, seguridade social e combate à Pobreza. Seminário sobre o salário mínimo. 2005.

Disponível em:

<http://www.eco.unicamp.br>.

MARQUES, R. M.; MENDES, A. O governo Lula e a contra-reforma previdenciária. São Paulo em Perspectiva, São Paulo, v. 18, n. 3, p. 3-15, 2004.

OCDE. Régimes de pension de la fonction publique. (Documents Sigma, n. 10). Paris: OCDE, 1997. ORNELAS, W. O novo modelo previdenciário brasileiro: uma fase de transição. In: FÓRUM NACIONAL, 11. Brasília, MPAS, maio 1999.
PINHEIRO, V. C. Aspectos sociais da Previdência Social no Brasil: o desafio de aumentar a cobertura. In: CONGRESSO INTERNACIONAL DE TÉCNICAS ATUARIAIS E GERENCIAMENTO FINANCEIRO. Curitiba: AISS e MPAS, maio 2000.

STERDYNIAK, H.; VILLA, P. Pour une reforme du financement de la sécurité sociale. Revue de l'OCDE, n. 67, oct. 1998. OCDE: Paris, 1998.

SUPLICY, Eduardo. M. Renda de cidadania: a saída é pela porta. São Paulo: Cortez Editores, 2002.

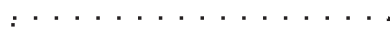

E-mail de contato da autora:

rosamarques@hipernet.com.br 